\title{
Review: $\alpha$ glucosidase inhibitors improve glycaemic control but have uncertain effects on patient-important outcomes in type 2 diabetes
}

Van de Laar FA, Lucassen PL, Akkermans RP, et al. Alpha-glucosidase inhibitors for type 2 diabetes mellitus. Cochrane Database Syst Rev 2005;(2):CD003639.

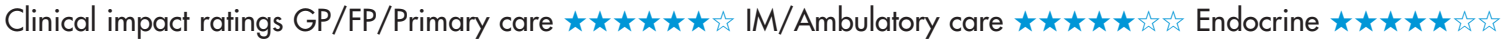

In patients with type 2 diabetes mellitus, are $\alpha$ glucosidase inhibitors effective for improving glycaemic control?

\section{METHODS}

\section{Data sources: Medline (to April 2003), EMBASE/Excerpta Medica (to April 2003), the Cochrane Central Register of Controlled Trials (Issue 3, 2003), LLACS (to April 2003), databases of ongoing trials (all to April 2003), Current Contents (to December 2003), contacting experts and manufacturers, and bibliographies of relevant studies.

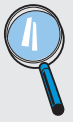 \\ Study selection and assessment: randomised controlled trials (RCTs) in any language with $\geqslant 12$ weeks' duration that compared $\alpha$ glucosidase inhibitor monotherapy with any other intervention in patients with type 2 diabetes and included $\geqslant 1$ predefined clinical outcome. Study quality assessment included randomisation, allocation concealment, blinding, and attrition. \\ Outcomes: glycaemic control, lipid concentrations, body weight, adverse effects, mortality, diabetes related morbidity, and quality of life.}

\section{MAIN RESULTS}

41 RCTs $(n=8130)$ were included. Most studies were 24 weeks in duration. $\alpha$-glucosidase inhibitors improved glycated haemoglobin and fasting blood glucose concentrations (table). Lipid concentrations and body weight were not affected. Acarbose was associated with a greater risk of gastrointestinal adverse effects than placebo (table). Acarbose and sulphonylureas did not differ for glycated haemoglobin or fasting blood glucose concentrations. Data were lacking on the effects of $\alpha$ glucosidase inhibitors on mortality, diabetes related morbidity, and quality of life.

\section{CONCLUSIONS}

In patients with type 2 diabetes, $\alpha$ glucosidase inhibitors improve glycaemic control in studies of mainly 24 weeks' duration. Data are lacking on the effects of $\alpha$ glucosidase inhibitors on mortality, diabetes related morbidity, and quality of life.

Abstract and commentary also appear in ACP Journal Club.

For correspondence: Dr F Van de Laar, University Medical Centre Nijmegen, Nijmegen, The Netherlands. f.vandelaar@hag.umcn.nl

Source of funding: no external funding.

\section{Commentory}

Glucosidase inhibitors are sparsely used in the US compared with some other countries because of their modest efficacy and untoward gastrointestinal side effects, particularly "hyperflatulence." $\alpha$ Glucosidase inhibitors produce very modest improvements in glycaemic control, primarily affecting postprandial glucose excursions. The $0.2 \%$ lowering of glycated haemoglobin over 3 years seen in the $\mathrm{UKPDS}^{1}$ is probably closer to real world experience.

The publication of the STOP-NIDDM trial, ${ }^{,}$showing greater reductions in cardiovascular events and hypertension in patients with impaired glucose tolerance treated with acarbose than with placebo, has caused physicians to rethink the utility of these drugs. A 2004 meta-analysis $^{3}$ of studies with 52 weeks' follow up showed a $64 \%$ reduction in myocardial infarction with acarbose compared with placebo. Whither the difference with the meta-analysis by Van de Laar et al? 5 of the 7 studies included in the 2004 review did not meet the stringent criteria for inclusion in this meta-analysis. 2 were unpublished studies with data available only from the manufacturer. Hence the analyses and conclusions between the 2 reviews are hardly comparable. At best, data indicating that $\alpha$ glucosidase inhibitors are cardioprotective are not compelling.

The problematic side effects and limited efficacy of $\alpha$ glucosidase inhibitors make them unlikely to be a mainstay of diabetic therapy. This view has been voiced in official public pronouncements in Europe. ${ }^{45}$ I see no reason to differ.

$$
\begin{array}{r}
\text { William L Isley, MD } \\
\text { Mayo Clinic } \\
\text { Rochester, Minnesota, USA }
\end{array}
$$

1 Holman RR, Cull CA, Turner RC. A randomized double-blind trial of acarbose in type 2 diabetes shows improved glycemic control over 3 years (UK Prospective Diabetes Study 44). Diabetes Care 1999;22:960-4.

2 Chiasson JL, Josse RG, Gomis R, et al. Acarbose treatment and the risk of cardiovascular disease and hypertension in patients with impaired glucose tolerance: the STOP-NIDDM trial. JAMA 2003;290:486-94.

3 Hanefeld M, Cagatay M, Petrowitsch T, et al. Acarbose reduces the risk for myocardial infarction in type 2 diabetic patients: meta-analysis of seven long-term studies. Eur Heart J 2004:25:10-6.

4 Mclntosh A, Hutchinson A, Home PD, et al. Clinical guidelines and evidence review for type 2 diabetes: management of blood glucose. Sheffield, UK: School of Health and Related Research, University of Sheffield, 2001.

www.nelh.nhs.uk/guidelines db/html/fulltext-appendix/

Bloodglucose2.html (accessed 14 Oct 2005).

5 Rutten GE, Verhoeven S, Heine RJ, et al. Guidelines on type 2 diabetes.

\begin{tabular}{|c|c|c|c|c|c|}
\hline Comparisons & $\begin{array}{l}\text { Number of } \\
\text { comparisons ( } n \text { ) }\end{array}$ & Outcomes & \multicolumn{3}{|c|}{ Weighted mean difference $(95 \% \mathrm{Cl})$} \\
\hline \multirow[t]{2}{*}{$\begin{array}{l}\text { Acarbose } v \text { placebo } \\
\text { Miglitol } v \text { placebo } \\
\text { Voglibose } v \text { placebo } \\
\text { Acarbose } v \text { placebo } \\
\text { Miglitol } v \text { placebo } \\
\text { Voglibose } v \text { placebo }\end{array}$} & $\begin{aligned} 28 & (2831) \\
7 & (1088) \\
1 & (238) \\
28 & (2838) \\
2 & (398) \\
1 & (234)\end{aligned}$ & $\begin{array}{l}\text { Change in glycated haemoglobin } \\
(\%) \\
\text { Change in fasting blood glucose } \\
(\mathrm{mmol} / /[\mathrm{mg} / \mathrm{dl}])\end{array}$ & \multicolumn{3}{|c|}{$\begin{array}{l}-0.8(-0.9 \text { to }-0.6) \\
-0.7(-0.9 \text { to }-0.4) \\
-0.5(-0.6 \text { to }-0.3) \\
-1.1(-1.4 \text { to }-0.8)[-19.8(-14.4 \text { to }-25.2)] \\
-0.5(-0.9 \text { to }-0.2)[-9.0(-3.6 \text { to }-16.2)] \\
-0.6(-1.0 \text { to }-0.2)[-10.8(-3.6 \text { to }-18)]\end{array}$} \\
\hline & & & Event rates & RRI (CI) & NNH (CI) \\
\hline Acarbose $v$ placebo & $4(1442)$ & Gastrointestinal adverse effects & $59 \%$ v $34 \%$ & $86 \%(60$ to 110$)$ & $4(3$ to 5$)$ \\
\hline
\end{tabular}
Huisarts Wet 2000;42:67-84.

$\alpha$ Glucosidase inhibitors $v$ placebo in type 2 diabetes*

*Abbreviations defined in glossary; RRI, NNH, and Cl calculated from data in article using a random effects model. Most studies were 24 weeks in duration. 